\title{
Crisis and Collapses in Stock Exchanges and Chaos Theory
}

\author{
A. Kipouros \\ Dept. of Accounting, Kavala Institute of Technology, Kavala, Greece
}

\section{Introduction}

In 1993 a critical and symbolic article, on the existing theoretical models and approaches of modern finance science, with regard to their methodological validity to explain the reality of finance, was published. The great epistemological importance of the article between the existing theoretical models, was about the efficiency of interpretation of financial phenomena and their economic repercussions for companies and investors.

This constitutes a turning-point, to replay the central question of finance, about the interpretiveness of the dogma, methodology and models used, with regard to the reality of approach to explain the financial phenomena.

This article deals with the degree of interpretiveness of the various theories and models of the modern Financial Theory.

It was written by the Nancy Nickols [1], co-publisher of "Harvard Business Review" journal of 1993, with the title «Efficient? Chaotic? What 's the new finance».

Until this time, for the interpretation of prices evolution and changes in stock exchanges, there were two main theories:

a)the approach of rational investor, acting in the Efficient Markets (Efficient Market Hypothesis), where prices are moving as a reflection to new information.

b)the approach of the "Chaotic" way of price movements.

Questions about dogmatic foundation and methodology about the interpretiveness of various theoretical approaches.

The explanatory options about Crisis and collapses under the complexity and volatility of markets

After Eugene Fama"s [2] new proposal (that revisioned his old theory and model), about substantiality and reality of explanation of the several existing models for stocks pricing (CAPM, ICAPM, APT e.t.c.), he was introduced the "RANDOM WALK THEORY", after the new research results, about the reasons of price movements.

After the acceptance of this theory, other scientists

*E-mail address: akipouros@teikav.edu.gr ISSN: 1791-2377 (C) 2011 Kavala Institute of Technology. All rights reserved. introduced the "Chaos theory" and the "theory of asymmetrical information", with a fast introduction of suitable new mathematic and statistical techniques, that could describe better the dynamic evolutions in markets and prices.

The latest approaches of the financial management and financial policy are based upon the:

1. Non-linear dynamic analysis and chaos theory, as the new scientific financial paradigm.

2. based on the acceptance that investors are not always "rational" according to the CAPM.

3. new finding of Eugene Fama, that the measure of instability of the stock prices beta $(\beta)$, is under ambiguity to give the real impacts of market volatility to stock prices.

4. The wide acceptance of "Random Walk" theory to explain and interpret stock prices and after this the necessity to use chaos theory to analyze the real dynamic of financial phenomenon that affects their behavior.

After these evolutions Steven Ross [3] Introduced the theory about «multifactorial model» of «ARBITRAGE PRICING THEORY-APT», but this model also was not enough to explain the evolutions of market prices despite the opinion that was better than the CAPM to explain the stock prices.

After this, other researchers using econometrical models found the existence of "market anomalies" in the way of price configuration.

Professor Shiller [4] followed with his book titled “Whose minding the store?" He introduces the school of "Revisionists", saying that the markets are mainly unpredictable at least with the CAPM's approach.

Thu, he proposes a new more sophisticated method and model to explain the market dynamics.

\section{Chaos and Market Behavior}

The pioneers of the application of chaos theory were Doyne Farmer [5] and Norman Packard [6], who began the effort to predict the roulette outcomes in Las Vegas casinos, analyzing the movements of the most sensitive tendencies of factors, in order to predict the outcome of the proceeded 
event that happens to depend strongly on the initial conditions and contingences of the system mechanisms.

After the projections and the admission of this chaotic methodology, they tried to apply it on stock and commodities exchanges, where they had either profits or losses, the final result was the Improvement of the predictionality of this method about chaotic behavior.

Also they wanted to find the final results/outcomes, by a big number of system equations, that describes the evolutionary dynamic of the roulette game and of course to transfer this to the market system

In 1991, Edgar Peters [7] a Fund manager from Boston, wrote a book with the title "Chaos and order in capital markets", explaining the application of chaos theory in Economics and specially in capital markets.

In his theory after the assumptions were set, he proves and projects that the markets are not always well standing according to their order, but they have functional gaps.

So markets are not simple and linear mechanisms, but a complex composition of interdependencies, (giving so a new model and methodology about the "investing behavior" and the predictions of market fluctuations).

After this, Bryan Arthur [8], combined a group of physicists mathematicians and economists who studied the issue of market prediction searching for the "positive feedbacks" in the economy, suggesting an investing strategy based on the past comparative advantages processed by the firm in long time period (behavior, situation practices and outcomes.

\section{The Synthesis of Economophysics and Impacts in Economic and Financial Theory and Predictability.}

Chaotic approach in the decision-making in the capital markets-cases

The use of "chaotic approach" changes now the decisionmaking on transactions of Stock Exchanges not only in the base of the "new information", is diffused "asymmetrically".

This is the problem, because from these new information, springs the new estimation of market, factors that are changes the decisions to buy or sale, that reflects the new estimations of market for the running internal value of each stock

Thus the market has continuously new points of balance", in different level from time to time and anticipates the "new levels of prices".
The model has a «non- linear dependence» in the process of configuration and change of prices.

The stock exchanges and their chaotic behaviour

The change of situations is great, because the developments in the wider environment of economy and differences of policies and new evolutionary determinations in capital markets.

Shaping a complex system of effects and continuously altered results

The capital markets therefore are presenting in their developments, all the following characteristics, operations and significances of complexity and chaotic behaviour.

The significances of complexity and chaos, as operations and results, it is reported of course in characteristics that present the stock exchanges

Summarising the above mentioned we have to say:

The "non linearity" is expressed with the continuous change of initial conditions, that means that, two initially similar totals of prices of variables of a system, as a rule (in a dynamic system) can deviate particularly evolutionar throughout the time.

Thus in the "space of phases" of a system, coexist simultaneously "regions of chaos", with regions of "more organised regions", under a linear order with a deterministic behavior of their variables.

The chaos, while giving the impression of "nonexistence of organisation", that leads to random/accidental or unanticipated behavior, is however very different from the clean chance.

The chaos has his own "internal laws" and ostensibly resembles with ordinary/chance because it has a probabilistic determinism (likelihood).

Actually it has "cohesiveness of propensity", after we can distinguish in some degree the "moment generating» variables, in the Stock Exchange markets and the financial system, with interrelation of probability.

The most common application of "chaotic approach", is in the analysis of "chaotic time series", where under the influence of theory of the " Random walk of prices", we consider that "the return/performance of prices of securities in the capital markets is result of meditative process".

The chaos (in the theoretical perception as in mathematics, also in social sciences) is an event or a "phenomenon of discontinuity" of functional structured situation of subsystems or situation of things (status quo).

\section{References}

1. Nichols, Nancy A. "Efficient? Chaotic? What's the New Finance?" Harvard Business Review, 71(5):00178012,(1993)

2. Fam, Eugene "Random Walks in Stock Market Prices". Financial Analysts Journal 51 (1). September-October, (1965)

3. Ross, S." The arbitrage theory of capital asset pricing". Journal of Economic Theory 13, 341-60,(1976).

4. Shiller,R Ph.D., "Integrating Investing with Social Sciences," Journal of Investment Consulting ,7(1): 1020,(2004)

5. $\quad$ Farmer, J. D. "Slippage 1996." Technical Report, Prediction Company, Santa Fe, NM, (1996).

6. Packard, Norman, "Adaptation Toward the Edge of Chaos", (1988)
7. Edgar Peters.E.," Chaos and Order in Capital Markets" , John Wiley and Sons, Inc, (1996)

8. Arthur,W.B., Econ. Journal, 99, 116, (1989) 